Cahiers $d u$ MONDE RUSSE

\section{Cahiers du monde russe}

Russie - Empire russe - Union soviétique et États indépendants

$43 / 4 \mid 2002$

Intellectuels et intelligentsia

\title{
Virgil Krapauskas, Nationalism and historiography
}

\section{Daniel Beauvois}

\section{(2) OpenEdition \\ Journals}

Édition électronique

URL : https://journals.openedition.org/monderusse/4050

DOI : 10.4000/monderusse. 4050

ISSN : $1777-5388$

Éditeur

Éditions de l'EHESS

Édition imprimée

Date de publication : 30 décembre 2002

Pagination : 778-780

ISBN : 2-7132-1796-2

ISSN : $1252-6576$

Référence électronique

Daniel Beauvois, «Virgil Krapauskas, Nationalism and historiography », Cahiers du monde russe [En ligne], 43/4 | 2002, mis en ligne le 17 juin 2009, consulté le 03 septembre 2022. URL : http:// journals.openedition.org/monderusse/4050; DOI : https://doi.org/10.4000/monderusse.4050

Ce document a été généré automatiquement le 3 septembre 2022.

Tous droits réservés 


\title{
Virgil Krapauskas, Nationalism and historiography
}

\author{
Daniel Beauvois
}

\section{RÉFÉRENCE}

Virgil KRAPAUSKAS, Nationalism and historiography. The case of nineteenth-

century Lithuanian historicism. Boulder, East European Monographs ; New York, Distr. by Columbia University Press, 2000, $234 \mathrm{p}$.

1 Ce livre présente les auteurs et les ouvrages qui ont le plus contribué, au XIX siècle avec de nombreux rappels en amont et en aval - à une vision séparée de la Lituanie, principalement ceux qui ont mis l'accent sur la rupture avec la Pologne et, très secondairement, avec tout ce qui n'était pas ethniquement lituanien. Le nationalisme y est donné pour une valeur positive, ce qui induit une ligne méthodologique dont on perçoit souvent mal le fondement. L'auteur semble vouloir convaincre que la vision intrinsèquement "lituanienne» du passé a évolué de manière historiciste et s'est acheminée vers une approche de plus en plus scientifique qui a permis d'atteindre une certaine " vérité historique ». Mais cet effort de présentation est sans cesse contredit par les hommes et les matériaux présentés - qui relèvent très largement de la mythographie et dont l'importance n'est apparue qu'avec un considérable décalage dans le temps. Il en est ainsi de Simonas Daukantas (1793-1864), présenté en un chapitre particulier (p. 63-86) parce qu'il fut le premier « historien » à écrire en lituanien, en 1838, mais dont l'œuvre ne fut éditée aux États-Unis qu'en 1893-1897. L'œuvre de ce "prophète» de la renaissance nationale n'a de valeur que par la force «mythogénique » de sa vision d'une Lituanie païenne, toute pénétrée d'harmonie rousseauiste, et par la création d'un monde imaginaire résolument opposé au christianisme acculturant apporté par l'union avec la Pologne. On est très loin de l'histoire.

2 Le chapitre suivant, intitulé « Deux historiens scientifiques» (p. 87-105), est encore plus trompeur, dans la mesure où ni Simonas Stanievičius (1799-1848), ni l'évêque Motiejus 
Valančius (1801-1875) ne furent des savants. Le premier (inédit jusqu'en 1967 !) ne rejetait pas encore complètement la légende des origines romaines (Palémon) des Lituaniens et le second - dont le rôle d'éducateur est incontestable - s'illustra surtout par de petits livrets de morale pratique pour enfants. Quant au groupe des rédacteurs du journal Aušra (L'Aurore) qui ne dura que de 1883 à 1886 et que l'on présente comme le point de départ de la Lituanie moderne, il est bien difficile d'y trouver les influences positivistes polonaises, voire socialistes russes, qu'évoque rapidement l'auteur. La vision " historique » de Janas Basanavičius (1851-1927), grand amateur de folklore et collecteur de chants populaires, tendait encore à trouver des origines thraces ou phrygiennes aux Lituaniens, développait des élucubrations pseudo-linguistiques sur des consonances de vocabulaire plus que douteuses. On retrouve tout cela chez Jonas Šliọpas qui, après son émigration aux États-Unis comme médecin, se fit connaître là-bas, en dépit de ses convictions positivistes et laïques, comme l'auteur d'un "élaborat», encore bien romantique, intitulé Les ancêtres des Lituaniens en Asie Mineure (Chicago, 1899). Le livre s'achève sur un chapitre consacré aux vulgarisateurs, surtout catholiques, du groupe, gravitant au début du xx $\mathrm{x}^{\mathrm{e}}$ siècle autour du journal anti-tsariste Varpas (La Cloche).

Il eût mieux valu assumer clairement cette longue tradition de l'imaginaire et du légendaire, dans la réémergence du peuple lituanien, et ne pas essayer de l'insérer dans l'« historicisme ». À condition de le prendre pour ce qu'il est - une étude détaillée du rôle « natiogénique » des mythes -, ce livre, grâce à un appareil de notes très fourni et une bibliographie abondante, est le manuel le plus utile qui soit.

Il reste à souligner que si la Lituanie veut entrer dans l'Union européenne, elle ne peut enfermer son histoire dans cette vision lituano-lituanienne. Peut-être l'auteur s'attachera-t-il maintenant (il s'agit de la thèse de doctorat d'un jeune chercheur) à développer tout ce que l'historiographie de son pays d'origine doit aux Polonais, aux Allemands, aux Russes. On s'étonne en effet de la minceur des allusions portant sur les études des trois versions ruthènes du Statut lituanien $d u x I^{e}$ siècle. Les travaux des historiens ou juristes de l'université de Vilna avant 1831 (Lelewel, Onacewicz, Danilowicz), ou des commissions de réforme du droit constituées à Saint-Pétersbourg, avant 1841, sont capitaux pour rappeler la grandeur de l'État lituanien à travers trois siècles de ruthénisation, bien avant ses trois siècles de polonisation. La recherche est aussi, désormais, beaucoup plus facile, depuis que Patricia Kennedy Grimsted a retrouvé toute la chaîne de la fameuse Metryka ruska jusqu'à la fin du XVII e siècle. Enfin, il faudrait accorder une place bien plus grande au rôle de Russes comme Lobojko, Rumjancev, Fortunatov, ou à celui de tous les savants allemands de Koenigsberg ou Tilsitt qui étaient parvenus, au début du xx $x^{e}$ siècle, à une telle connaissance de l'histoire, de la culture et de la langue lituanienne qu'ils faillirent bien imposer un roi allemand (Mindogas II !) à la Lituanie ressuscitée de 1918.

5 Bref, si une touche de patriotisme est pardonnable, le nationalisme est une impasse, en historiographie comme ailleurs. L'inaccessible « vérité historique » ne peut être approchée que dans le recul, la distance, le relativisme. Une démarche multiculturaliste eût semblé meilleure pour tenter de se défaire du «natiocentrisme» qu'il ne faut connaître, me semble-t-il, que pour s'en débarrasser. 